\title{
Islet $\beta$-cell-produced NUCB2/nesfatin-1 maintains insulin secretion and glycemia along with suppressing UCP-2 in $\beta$-cells
}

\author{
Yifei Yang ${ }^{1,2,3} \cdot$ Boyang Zhang ${ }^{1,4} \cdot$ Masanori Nakata ${ }^{1,4} \cdot J_{\text {Jun Nakae }}^{5} \cdot$ Masatomo Mori $^{6} \cdot$ Toshihiko Yada $^{1,2,3}(0)$
}

Received: 5 April 2019 / Accepted: 11 June 2019 / Published online: 21 June 2019

(c) The Physiological Society of Japan and Springer Japan KK, part of Springer Nature 2019

\begin{abstract}
Nesfatin-1 is a hypothalamic anorexigenic peptide processed from nucleobindin 2 (NUCB2). Central and peripheral administration of NUCB2/nesfatin-1 enhances glucose metabolism and insulin release. NUCB2/nesfatin-1 is also localized in pancreatic islets, while its function remains unknown. To explore the role of pancreatic $\beta$-cell-produced NUCB2/nesfatin-1, we developed pancreatic $\beta$-cell-specific NUCB2 knockout ( $\beta$ NUCB2 KO) mice and NUCB2 gene knockdown (shNUCB2) MIN6 $\beta$-cell line. In $\beta$ NUCB2 KO mice, casual blood glucose was elevated from 12 weeks of age. In a glucose tolerance test at 12 weeks, insulin secretion at 15 min was reduced and blood glucose at $2 \mathrm{~h}$ increased in $\beta$ NUCB2 KO mice fasted $8 \mathrm{~h}$. In islets isolated from $\beta$ NUCB2 KO mice, high glucose-stimulated insulin secretion (GSIS) was impaired. In shNUCB2 MIN6 cells, GSIS was reduced and UCP-2 mRNA expression was elevated. These results show impaired GSIS possibly associated with UCP- 2 overexpression in NUCB2-silenced $\beta$-cells, suggesting that $\beta$-cell-produced NUCB2/nesfatin- 1 maintains GSIS and thereby glycemia.
\end{abstract}

Keywords NUCB2 $\cdot$ Nesfatin-1 $\cdot$ Insulin secretion · Islet $\beta$-cell · MIN6 · UCP-2

\section{Introduction}

Nesfatin-1 (nucleobindin2-encoded satiety and fat-influencing protein-1) was initially discovered as a hypothalamic feeding inhibitory peptide processed from its precursor nucleobindin 2 (NUCB2) [1]. NUCB2 consists of 420

Toshihiko Yada

tyada@jichi.ac.jp

1 Division of Integrative Physiology, Department of Physiology, Jichi Medical University School of Medicine, Shimotsuke, Tochigi 329-0498, Japan

2 Division of Integrative Physiology, Kansai Electric Power Medical Research Institute, 1-5-6 Minatojimaminamimachi, Chuou-ku, Kobe 650-0047, Japan

3 Division of System Neuroscience, Kobe University Graduate School of Medicine, Kobe 650-0017, Japan

4 Department of Physiology, Wakayama Medical University School of Medicine, Wakayama 641-8509, Japan

5 Center for Medical Science, International University of Health and Welfare, 2600-1 Kitakanemaru, Ohtawara 324-8501, Japan

6 Kitakanto Molecular Novel Research Institute for Obesity and Metabolism, Midori, Gunma 379-2311, Japan amino acids and is processed into three fragments; nesfatin-1 (residues 1-82), nesfatin-2 (residues 85-163), and nesfatin-3 (residues 166-396) [2]. Nesfatin-1 is also known as DNA binding/EF-hand/acidic protein (NEFA) [1, 3, 4]. Nesfatin-1 is highly conserved in humans, rats, and mice [1].

Intracerebroventricular (i.c.v) injection of nesfatin-1 reduces food intake and body weight along with recruiting several hypothalamic peptides regulating feeding and energy expenditure [1, 5-7]. Furthermore, i.c.v. injection of antibodies against nesfatin- 1 and antisense morpholinos against nesfatin-1 increases food intake and body weight in rats [1], indicating that the endogenous nesfatin-1 in the brain participates in regulation of appetite and body weight [8]. It was shown that peripheral administration of nesfatin-1 also suppresses feeding [8].

Nesfatin-1 is also expressed outside the brain, including adipocytes, gastric endocrine cells, and islet cells [9-11]. In healthy adults, oral administration of glucose, compared to saline, significantly elevates plasma nesfatin-1 levels [12]. Furthermore, intravenous injection of nesfatin-1 significantly decreases blood glucose levels in hyperglycemic db/ $\mathrm{db}$ mice [13]. In addition, nesfatin-1 directly acts on mouse islet $\beta$-cells and MIN6 cells to enhance glucose-stimulated insulin secretion (GSIS) [14, 15]. These findings suggest 
possible roles of nesfatin-1 in the regulation of glucose metabolism in the health and type 2 diabetes via mechanisms involving an enhancement of insulin release [16-20].

Notably, NUCB2/Nesfatin-1 is reportedly expressed abundantly in pancreatic islet $\beta$-cells $[14,15,21-23]$. However, the role of the endogenous nesfatin-1 in pancreatic islet $\beta$-cells is unknown. Islet $\beta$-cells are the tissue that exclusively secretes insulin to primarily regulate glycemia, and dysfunction of $\beta$-cells leads to diabetes. Hence, we hypothesized that the NUCB2/nesfatin- 1 born in islet $\beta$-cells severs as an intracellular and/or autocrine regulator of $\beta$-cells. This study aimed to explore the role of islet $\beta$-cell nesfatin- 1 in regulating insulin secretion in islet $\beta$-cells.

In this study, we analyzed C57BL/6 mice in which NUCB2/nesfatin-1 is knockout specifically in islet $\beta$-cells by Cre-loxP system ( $\beta$ NUCB2 KO). Furthermore, to get a hint for the molecules possibly regulated by NUCB2/nesfatin- 1 in $\beta$-cells, we produced and analyzed a $\beta$-cell line MIN6 cells in which NUCB2 gene expression was silenced (shNUCB2 MIN6 cells).

\section{Methods}

\section{Animals}

Pancreatic $\beta$-cells-specific NUCB2/nesfatin-1 KO ( $\beta$ NUCB2 $\mathrm{KO})$ mice were generated by mating rat insulin 2 Cre knockin C57BL/6 mice (RIP-Cre) (provided by Dr. Jun Nakae, International University of Health and Welfare) with NUCB2-floxed C57BL/6 mice by loxP sites flanking exons (provided by Dr. Masatomo Mori, Kitakanto Molecular Novel Research Institute for Obesity and Metabolism). Male mice were single housed for in vivo experiments and group housed for in vitro experiments under a 12-h light/dark cycle (7:30 am light on). Animals were fed regular chow food (CE-2; Japan CLEA). Water and food were available ad libitum except particular experiments in which food was withdrawn. All animal procedures were approved by Jichi Medical University Animal Care and Use Committee and by the Committee on Animal Experimentation of Kobe University.

\section{Construction of short hairpin RNAs (shRNAs) and viral vector production in MIN6 cells}

The $\beta$-cell line, MIN6 cells [24, 25], were maintained in DMEM with high glucose (Life Technologies, Inc., Grand Island, NY, USA) supplemented with $20 \%$ fetal bovine serum, $100 \mathrm{units} / \mathrm{ml}$ penicillin, $100 \mu \mathrm{g} / \mathrm{ml}$ streptomycin sulfate, and $0.5 \%$ 2-mercaptoethanol at $37{ }^{\circ} \mathrm{C}$.

Target sequence for mouse NUCB2 was chosen to design shRNAs (accession number NM 016773, 5'-GGATCA TCCAAGTACAGTA-3'; 298-316). In addition, scrambled oligonucleotide sequence was used for specificity control (5'-CAACACTAGTTGACATGTA-3'). NUCB2-shRNA (shNUCB2) and Scr-shRNA (shScr) viruses were produced after triple transfection of MIN6 cells with shRNA. For genome targeting assay, we achieved mutant efficiency for the puromycin-selected cell clones.

\section{Measurement of body weight and casual blood glucose}

Body weight and blood glucose were measured at 15:00 pm once a week. After tail cut with surgical scissors, blood was sampled for measuring blood glucose concentration using GlucoCard DIA meter (Arkray, Japan).

\section{Glucose tolerance test (GTT)}

Prior to GTT, mice were fasted for $8 \mathrm{~h}(7: 30-15: 30)$, and body weight was measured. Glucose at $2 \mathrm{~g} / \mathrm{kg}$ was administered intraperitoneally, and blood was taken from the tail. Blood glucose concentration was determined using GlucoCard DIA meter (Arkray, Japan) and plasma insulin using a Mouse Insulin ELISA kit (Morinaga Institute of Biological Science, Japan).

\section{Isolation of islets}

Islets were isolated from male mice aged 12 weeks by collagenase digestion method [26, 27]. Isolated islets were handpicked up under microscope in HKRB solution $(137 \mathrm{mM}$ $\mathrm{NaCl}, 5.6 \mathrm{mM} \mathrm{KCl}, 2.0 \mathrm{mM} \mathrm{CaCl} 2,1.2 \mathrm{mM} \mathrm{MgCl}_{2}, 1 \mathrm{mM}$ $\mathrm{NaH}_{2} \mathrm{PO}_{4}, 4.2 \mathrm{mM} \mathrm{NaHCO}{ }_{3}, 10 \mathrm{mM}$ HEPES [pH 7.4 with $\mathrm{NaOH}]$ ).

\section{Measurement of insulin secretion from islets and MIN6 cells}

Ten size-matched isolated islets were preincubated with HKRB containing $2.8 \mathrm{mM}$ glucose for $30 \mathrm{~min}$, and then test-incubated with HKRB containing $2.8 \mathrm{mM}$ or $8.3 \mathrm{mM}$ glucose for $30 \mathrm{~min}$ at $37{ }^{\circ} \mathrm{C}$. The medium was kept at $-80{ }^{\circ} \mathrm{C}$ until assay for insulin using Mouse Insulin ELISA kit (Morinaga Institute of Biological Science, Japan).

MIN6 cells, seeded into a 24-well plate at $1.4 \times 10^{5}$ cells per well, were preincubated with $500 \mu \mathrm{l}$ of HKRB containing $2.8 \mathrm{mM}$ glucose for $30 \mathrm{~min}$, and then test-incubated with $500 \mu \mathrm{l}$ of HKRB containing $2.8 \mathrm{mM}$ or $16.6 \mathrm{mM}$ glucose for $30 \mathrm{~min}$ at $37^{\circ} \mathrm{C}$. The insulin concentration was determined using insulin ELISA kit (Morinaga). 


\section{Western blotting}

Isolated mouse islets and MIN6 cells were homogenized with ice-cold SDS lysis buffer (2\% SDS, $20 \mathrm{mM}$ DTT, $1 \mathrm{mM}$ EDTA, $50 \mathrm{mM}$ Tris; pH 8.8). Proteins were separated by SDS-PAGE and electrophoretically transferred onto nitrocellulose membranes. Protein expression was detected using rabbit anti-NUCB2 (Sigma-Aldrich, St. Louis, MO, USA), peroxidase-labeled secondary antibody (Sigma), and enhanced chemiluminescence. Immunoreactive signal was quantified by using FAS-1000 (Fujifilm, Japan) and expression levels of proteins were normalized to $\beta$-actin (Santa Cruz Biotechnology, Inc, Santa Cruz, CA, USA).

\section{Real-time RT-PCR}

Total RNA was isolated from MIN6 cells using TRIzol reagent (Invitrogen, Carlsbad, CA, USA), and treated with RQ1-DNase (Promega, Madison, WI, USA) to eliminate contaminating genomic DNA. After the conversion to cDNA, real-time PCR was performed with SYBR premix Ex taq II polymerase (Takara Bio, Kusatsu, Shiga Prefecture, Japan). Expression levels were calculated by the $\Delta \Delta \mathrm{CT}$ method. Primer sets were as follows:

\section{UCP-2}

Forward primer 5'-CCCAATGTTGCTCGTAATGC-3' Reverse primer 5'-AGAAGTGAAGTGGCAAGGGA-3'.

\section{Immunohistochemistry}

The pancreas was dissected, fixed in $4 \%$ paraformaldehyde, embedded in paraffin, and sectioned. The paraffin-embedded sections were immunostained with anti-nesfatin-1 [1] (Ab24; 1:1000, provided from Gunma University, Japan) and antiinsulin (A0654; 1:200, Dako, Japan) antibodies.

\section{Statistical analysis}

The data are presented as mean \pm SE. Statistical significance was evaluated by one-way analysis of variance (ANOVA) followed by Tukey's multiple comparison test in Figs. 2a-c, 3 and $4 \mathrm{~b}$, and by unpaired $t$ test in Figs. $2 d$ and 4 c. $P$ values of $<0.05$ were considered statistically significant.

\section{Results}

\section{Generation of islet $\beta$-cell-specific NUCB2/nesfatin-1 knockout ( $\beta N U C B 2$ KO) mouse}

Immunofluorescence staining for nesfatin-1 was intense and largely overlapped with that for insulin in the pancreatic islets of Cre mice (Fig. 1a upper panel). The result indicated that NUCB2/nesfatin- 1 was expressed in $\beta$-cells. In the islets from $\beta$ NUCB2 KO mice, the immunofluorescence staining for nesfatin-1 was not observed, while that (a)
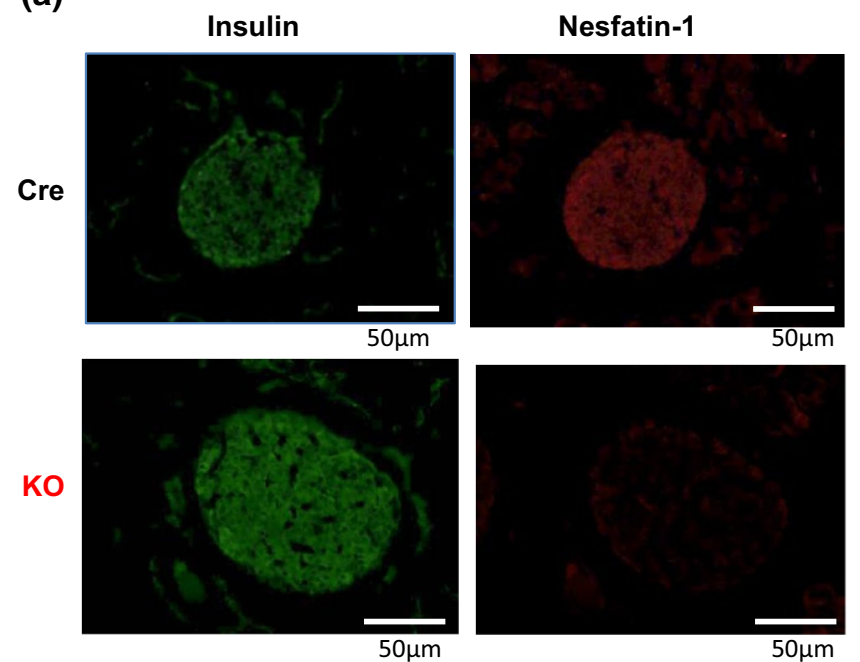

Fig. 1 Immunostaining for insulin and nesfatin-1 in pancreatic islets and hypothalamic arcuate nucleus of Cre and $\beta$ NUCB2 KO mice. a Double immunostaining for insulin and nesfatin-1 in islets. The upper rows show Cre mice and the lower rows $\beta$ NUCB2 KO mice. Left: insulin (green: Alexa 488 fluorescence), middle: nesfatin-1 (red: Alexa 594), right: merged images. $n=21$ islet sections from six
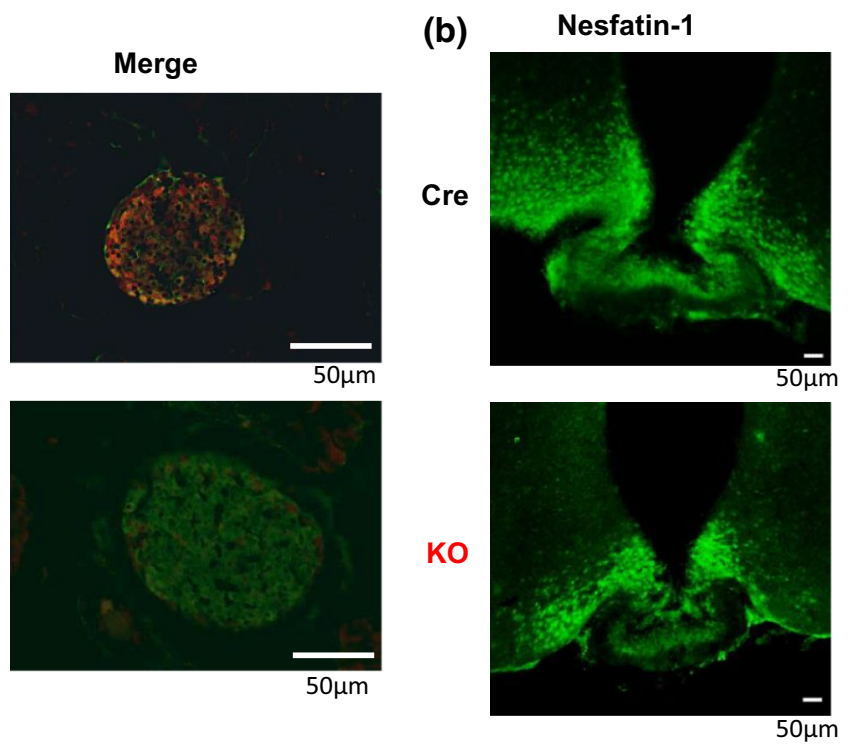

Cre mice, and $n=24$ islet sections from seven $\beta$ NUCB2 KO mice. b Immunostaining for nesfatin-1 (green: Alexa 488) in hypothalamic arcuate nucleus. Upper and lower panels show Cre and $\beta$ NUCB2 KO mice, respectively. $n=9$ sections from one Cre mice, and $n=9$ sections from one $\beta \mathrm{NUCB} 2 \mathrm{KO}$ mice. Scale bars: $50 \mu \mathrm{m}$ (color figure online) 
Fig. 2 Metabolic phenotypes of $\beta$ NUCB2 KO mice. Body weight (a) and casual blood glucose levels (b) in Cre $(n=6)$ and $\beta$ NUCB2 KO mice $(n=7)$ measured once every week. c Blood glucose levels at 0,30 , 60 , and $120 \mathrm{~min}$ of glucose tolerance test (GTT) in Cre mice $(n=5)$ and $\beta$ NUCB2 KO mice $(n=5)$ fasted for $8 \mathrm{~h}(7: 30-15: 30)$. d Plasma insulin concentrations at $15 \mathrm{~min}$ of GTT in Cre $(n=4)$ and $\beta$ NUCB2 KO mice $(n=4)$. GTT was performed after fasting for $8 \mathrm{~h}$ in mice aged 12 weeks. Values are mean \pm SEM. $* P<0.05$, $* * P<0.01$ between Cre and $\beta N U C B 2 \mathrm{KO}$ mice (a)

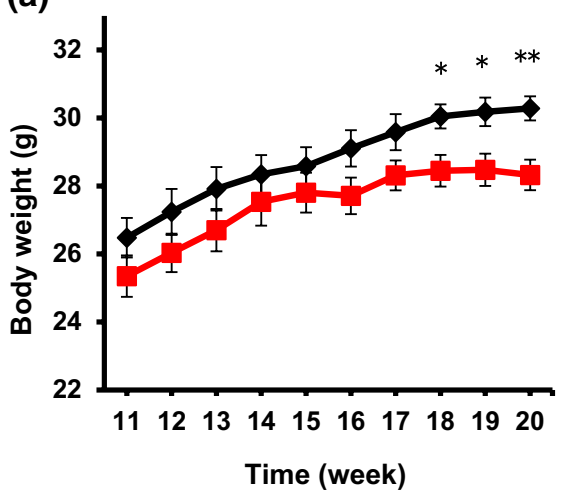

(c)

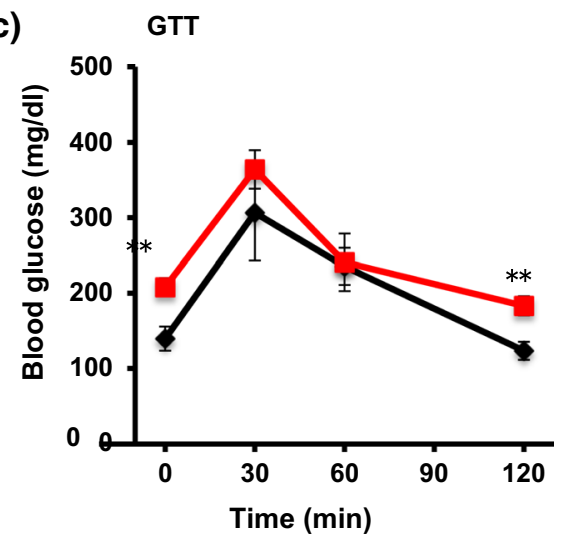

(b)

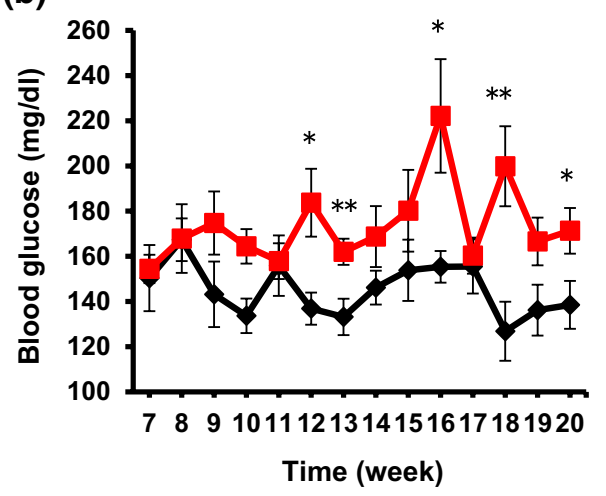

(d)

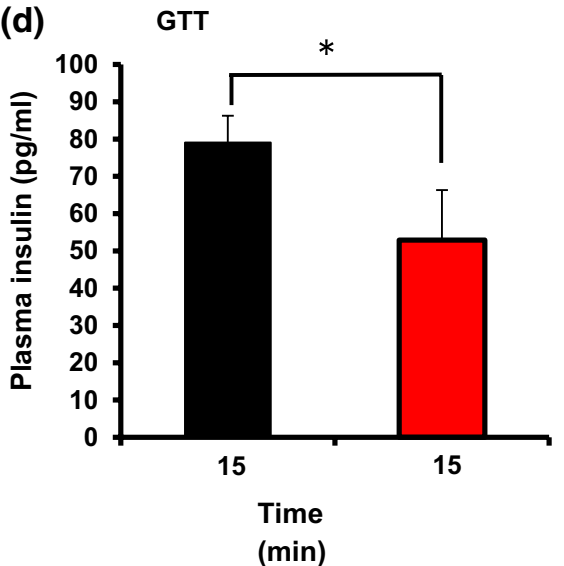

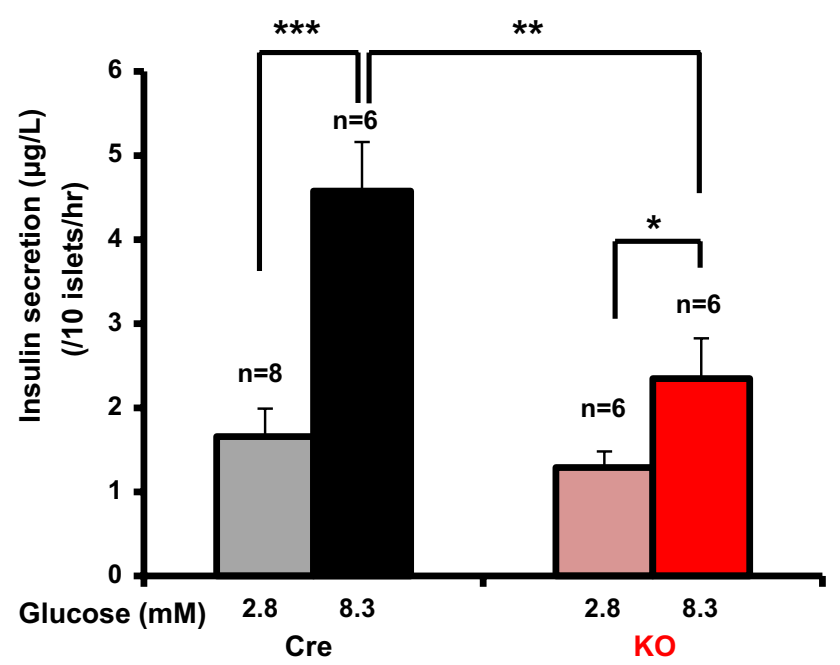

Fig. 3 Glucose induces insulin secretion from islets in $\beta$ NUCB2 KO mice to a lesser extent than in Cre mice. Basal insulin secretion from isolated islets under static incubation with $2.8 \mathrm{mM}$ glucose was not significantly different between Cre and $\beta$ NUCB2 KO mice. High glucose $(8.3 \mathrm{mM})$ significantly increased insulin secretion from isolated islets of both Cre and $\beta$ NUCB2 KO mice, and the increased level was significantly lower in $\beta$ NUCB2 KO than Cre mice. $n=8$ groups for $2.8 \mathrm{mM}$ Cre mice and $n=6$ groups for other. $* P<0.05$, $* * P<0.01$ and $* * * P<0.001$ for insulin was observed similarly to Cre mice (Fig. 1a lower panel). In the hypothalamic arcuate nucleus, in contrast, intense immunofluorescence staining for nesfatin-1 was observed in $\beta$ NUCB2 KO mice similarly to Cre mice (Fig. 1b). These results indicated that NUCB2/nesfatin-1 in islet $\beta$-cells was selectively deleted in $\beta$ NUCB2 KO mice.

\section{Elevated casual blood glucose, and increased blood glucose and reduced insulin secretion during GTT in BNUCB2 KO mice}

In $\beta$ NUCB2 KO mice, body weight (BW) was decreased at 18 weeks of age and later (Fig. 2a) and casual blood glucose was elevated at 12 weeks and later (Fig. 2b). In glucose tolerance test (GTT) at 12 weeks, blood glucose levels before and at $2 \mathrm{~h}$ after glucose injection were increased $(P<0.01)$ (Fig. 2c) and plasma insulin level at $15 \mathrm{~min}$ was reduced $(P<0.05)$ (Fig. 2d) in $\beta$ NUCB2 KO mice. However, blood glucose levels at $30 \mathrm{~min}$ and $60 \mathrm{~min}$ were not significantly elevated, which was in apparent disagreement with reduced plasma insulin level at $15 \mathrm{~min}$. This result suggested that a systemic factor other than insulin that lowers blood glucose might operate in $\beta N U C B 2$ KO mice. 
Fig. 4 NUCB2/Nesfatin-1 knockdown (shNUCB2) MIN6 cells exhibit impaired GSIS and elevated UCP-2 mRNA expression. a MIN6 cells were introduced with shRNA silencing scramble (shScr) and with shRNAs silencing NUCB2 at two different nucleotide sequences (shNUCB2 seq 1 and shNUCB2 seq 2). NUCB2 protein expression was reduced in shNUCB2 seq 1 MIN6 cells compared to shScr MIN6 cells and mouse islets. b Stimulation with $16.6 \mathrm{mM}$ glucose increased insulin secretion in shScr MIN6 cells but not in shNUCB2 seq 1 MIN6 cells under static incubation. c UCP-2 mRNA expression was elevated in shNUCB2 seq 1 MIN6 cells compared to shScr MIN6 cells

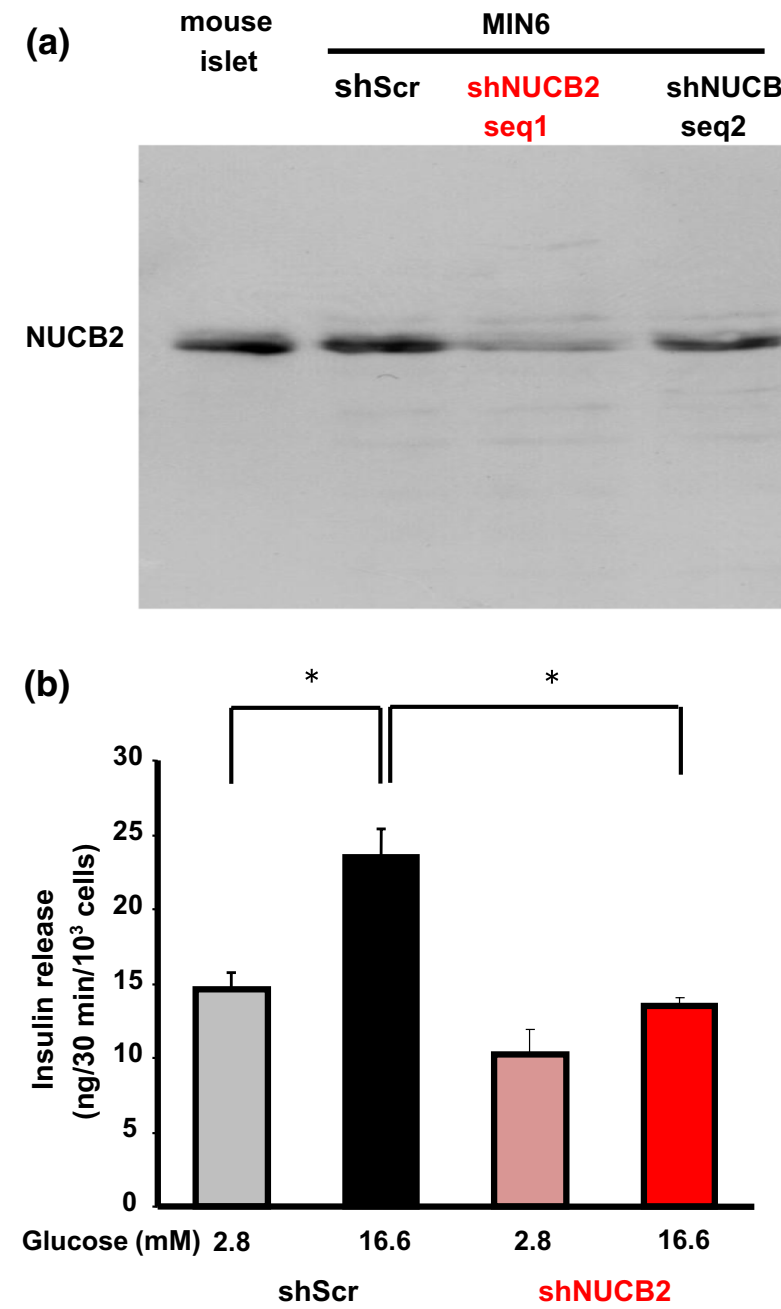

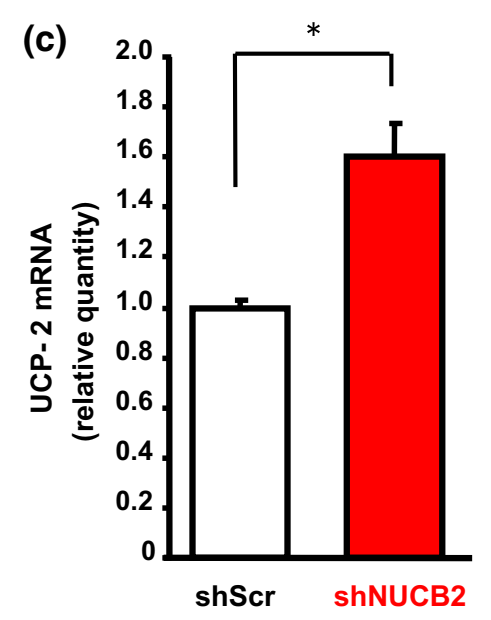

\section{Reduced GSIS in islets from $\beta N U C B 2$ KO mice}

In isolated islets from $\beta$ NUCB2 $\mathrm{KO}$ mice, basal insulin secretion under static incubation with $2.8 \mathrm{mM}$ glucose tended to be lower but not significantly compared to that in isolated islets from Cre mice (Fig. 3). Incubation with $8.3 \mathrm{mM}$ glucose significantly increased insulin secretion from islets of Cre $(P<0.001)$ and $\beta$ NUCB2 KO mice $(P<0.05)$, and the elevated level was significantly $(P<0.01)$ lower in islets of $\beta$ NUCB2 KO mice than Cre mice (Fig. 3).

\section{Reduced GSIS and elevated UCP-2 mRNA expression in shNUCB2 MIN6 cells}

Two types of nucleotide sequences in MIN6 cells into which NUCB2 shRNA was introduced were synthesized. Sequence 1 yielded a greater knockdown of NUCB2 protein expression in MIN6 cells (shNUCB2 MIN6 cells) to approximately $20 \%$ of that in control shScr MIN6 (Fig. 4a). Hence, the shNUCB2 MIN6 cells were used in the rest of study. In shNUCB2 MIN6 cells, basal insulin secretion under static incubation with $2.8 \mathrm{mM}$ glucose tended to be lower but not significantly compared to control shScr MIN6 cells (Fig. 3). Incubation with high glucose $(16.6 \mathrm{mM})$ significantly $(P<0.05)$ stimulated insulin secretion in shScr MIN6 cells, but not in shNUCB2 MIN6 cells (Fig. 4b). The amount of insulin secretion at $16.6 \mathrm{mM}$ glucose was significantly $(P<0.05)$ lower in shNUCB2 MIN6 than shScr MIN6 cells (Fig. 4b), a result similar to $\beta N U C B 2 \mathrm{KO}$ islets (Fig. 3). Furthermore, mRNA expression of UCP-2, a molecule that reduces ATP production, was significantly $(P<0.05)$ increased $(60 \pm 7.2 \%)$ in shNUCB2 MIN6 cells compared to shScr MIN6 cells (Fig. 4c).

\section{Discussion}

In this study, we found that $\beta$ NUCB2 KO mice exhibit late-onset elevation of casual blood glucose, as well as elevated blood glucose and lowered insulin secretion in GTT. In islets from $\beta N U C B 2$ KO mice, GSIS was significantly reduced. In shNUCB2 MIN6 cells, GSIS was reduced and 
UCP-2 mRNA expression was elevated. In addition, insulin secretion at basal glucose also tended to be lower in islets from $\beta$ NUCB2 KO mice and shNUCB2 MIN6 cells. These results indicate an impaired insulin secretion in NUCB2 KO $\beta$-cells possibly in part due to overexpression of UCP-2. This finding reveals a novel role of pancreatic $\beta$-cell-produced NUCB2/nesfatin-1 to enhance insulin secretion from islet $\beta$-cells, which may serve as a mechanism for auto-maintenance of insulin secretion by $\beta$-cells.

In $\beta$ NUCB2 KO mice, elevated blood glucose and reduced insulin secretion started at 12 weeks of age, while reduction of body weight started at 18 weeks. Furthermore, reduced body weight generally does not elevate blood glucose. Therefore, the elevated blood glucose and reduced insulin secretion appear to take place independently of the reduced body weight in $\beta$ NUCB2 KO mice. Inversely, reduced body weight may result from reduced insulin secretion. These data suggest that the impairment of glycemia and insulin secretion in $\beta$ NUCB2 KO mice are caused primarily by the alteration in pancreatic islets.

Administration of NUCB2/nesfatin-1 is known to potentiate GSIS in islet $\beta$ and MIN6 cells [15]. Here, we have revealed that the $\beta$-cell endogenous NUCB2/nesfatin- 1 functions to potentiate GSIS. Underlying mechanisms are largely unknown; two modes of action are conceivable. First, $\beta$-cell NUCB2/nesfatin-1 could function as an intracellular regulator. Second, NUCB2/nesfatin-1 could be released from and acts on $\beta$-cells to enhance insulin secretion, an autocrine action. However, further studies are needed to elucidate the action mode of the $\beta$-cell NUCB2/nesfatin-1.

The present study indicated that the pancreatic $\beta$-cells endogenous NUCB2/nesfatin-1 was associated with attenuation of hyperglycemia and promotion of insulin secretion, the properties considered anti-diabetic. These results fit with previous reports that intravenous injection of nesfatin-1 significantly decreases blood glucose levels in hyperglycemic $\mathrm{db} / \mathrm{db}$ mice [8] and that fasting nesfatin- 1 was significantly lower in type 2 diabetic patients [28]. On the other hand, our data are in apparent disagreement with previous reports that plasma levels of nesfatin-1 are increased in newly diagnosed type 2 diabetes patients $[12,15]$ and that NUCB2 mRNA and protein levels in muscle and adipose tissue of type 2 diabetes patients were markedly elevated compared to controls [29]. The cause of these contradictory data is still unknown. It may be due to differences in disease progression and sample population, or reflect a compensatory rise of plasma NUCB2/nesfatin-1 in some stage of type 2 diabetes. Further studies are needed to determine the role of NUCB2/nesfatin-1 levels in pathogenesis of diabetes. The results of the present study revealed a novel function of islet $\beta$-cell-produced NUCB2/nesfatin- 1 to enhance insulin secretion from islet $\beta$-cells, suggesting a possible anti-diabetic potential.
Acknowledgements This study was supported in part by the Grantin-Aid for Innovative Areas from Japan Society of the Promotion of Science to TY (26670453). TY is supported by the Advanced Research and Development Programs for Medical Innovation (AMED-CREST) from Japan Agency for Medical Research and Development (AMED).

Author contributions FY, MN, TY designed experiments. FY, MN, BZ conducted experiments. FY and MN analyzed data. FY, MN, TY prepared the manuscript. All authors evaluated and approved the manuscript.

\section{Compliance with ethical standards}

Conflict of interest The authors of this manuscript have no conflict of interest to declare.

Ethical approval All applicable international, national, and/or institutional guidelines for the care and use of animals were followed.

\section{References}

1. Oh-I S, Shimizu H, Satoh T, Okada S, Adachi S, Inoue K, Eguchi $\mathrm{H}$, Yamamoto M, Imaki T, Hashimoto K, Tsuchiya T, Monden T, Horiguchi K, Yamada M, Mori M (2006) Identification of nesfatin-1 as a satiety molecule in the hypothalamus. Nature 443(7112):709-712

2. Miura K, Titani K, Kurosawa Y, Kanai Y (1992) Molecular cloning of nucleobindin, a novel DNA-binding protein that contains both a signal peptide and a leucine zipper structure. Biochem Biophys Res Commun 187(1):375-380

3. Stengel A, Goebel-Stengel M, Wang L, Kato I, Mori M, Taché Y (2012) Nesfatin-1(30-59) but not the N- and C-terminal fragments, nesfatin-1(1-29) and nesfatin-1(60-82) injected intracerebroventricularly decreases dark phase food intake by increasing inter-meal intervals in mice. Peptides 35(2):143-148

4. García-Galiano D, Navarro VM, Gaytan F, Tena-Sempere M (2010) Expanding roles of NUCB2/nesfatin-1 in neuroendocrine regulation. J Mol Endocrinol 45(5):281-290

5. Shimizu H, Ohsaki A, Oh-I S, Okada S, Mori M (2009) A new anorexigenic protein, nesfatin-1. Peptides 30(5):995-998

6. Shimizu H, Oh-I S, Okada S, Mori M (2009) Nesfatin-1: an overview and future clinical application. Endocr J 56(4):537-543

7. Maejima Y, Sedbazar U, Suyama S, Kohno D, Onaka T, Takano E, Yoshida N, Koike M, Uchiyama Y, Fujiwara K, Yashiro T, Horvath TL, Dietrich MO, Tanaka S, Dezaki K, Oh-I S, Hashimoto K, Shimizu H, Nakata M, Mori M, Yada T (2009) Nesfatin-1-regulated oxytocinergic signaling in the paraventricular nucleus causes anorexia through a leptin-independent melanocortin pathway. Cell Metab 5:355-365

8. Shimizu H, Oh-I S, Hashimoto K, Nakata M, Yamamoto S, Yoshida N, Eguchi H, Kato I, Inoue K, Satoh T, Okada S, Yamada M, Yada T, Mori M (2009) Peripheral administration of nesfatin-1 reduces food intake in mice: the leptin-independent mechanism. Endocrinology 150(2):662-671

9. Foo KS, Brauner H, Ostenson CG, Broberger C (2010) Nucleobindin-2/nesfatin in the endocrine pancreas: distribution and relationship to glycaemic state. J Endocrinol 204(3):255-263

10. Cao X, Liu XM, Zhou LH (2013) Recent progress in research on the distribution and function of NUCB2/nesfatin-1 in peripheral tissues. Endocr J 60(9):1021-1027

11. Tsuchiya T, Shimizu H, Yamada M, Osaki A, Oh-I S, Ariyama Y, Takahashi H, Okada S, Hashimoto K, Satoh T, Kojima M, Mori 
M (2010) Fasting concentrations of nesfatin-1 are negatively correlated with body mass index in non-obese males. Clin Endocrinol (Oxf) 73(4):484-490

12. Zhang Z, Li L, Yang M, Liu H, Boden G, Yang G (2012) Increased plasma levels of nesfatin-1 in patients with newly diagnosed type 2 diabetes mellitus. Exp Clin Endocrinol Diabetes 120(2):91-95

13. Aydin S (2013) Multi-functional peptide hormone NUCB2/nesfatin-1. Endocrine 44(2):312-325

14. Gonzalez R, Reingold BK, Gao X, Gaidhu MP, Tsushima RG, Unniappan S (2011) Nesfatin-1 exerts a direct, glucose-dependent insulinotropic action on mouse islet $\beta$ - and MIN6 cells. J Endocrinol 208:R9-R16

15. Nakata M, Manaka K, Yamamoto S, Mori M, Yada T (2011) Nesfatin-1 enhances glucose-induced insulin secretion by promoting $\mathrm{Ca}(2+)$ influx through L-type channels in mouse islet $\beta$-cells. Endocr J 58(4):305-313

16. DeFronzo RA (1988) The triumvirate: $\beta$-cell, muscle, liver: a collusion responsible for NIDDM. Diabetes 37(6):667-687

17. Bogardus C (1996) Metabolic abnormalities in the development of non-insulin dependent diabetes mellitus. In: LeRoith D, Taylor SI, Olefaky JM (eds) Diabetes mellitus: A fundamental and clinical text. Lippincott-Raven, Philadelphia, pp 459-467

18. Algul S, Ozkan Y, Ozcelik O (2016) Serum nesfatin-1 levels in patients with different glucose tolerance levels. Physiol Res 65:979-985

19. Dai R, Deng G, Sun Z, Liu Z, Qian Y, Han Y (2017) Relation of serum and vitreous nesfatin- 1 concentrations with diabetic retinopathy. J Clin Lab Anal 31(5):e22105

20. Tang J, Yang Z, Liu F, Zhang Y, Liu J (2015) Changes in the serum levels of nesfatin-1 in type 2 diabetic patients with nephropathy. Diabetes/Metab Res Rev 31:21

21. Gonzalez R, Perry RL, Gao X, Gaidhu MP, Tsushima RG, Ceddia RB, Unniappan S (2011) Nutrient responsive nesfatin-1 regulates energy balance and induces glucose-stimulated insulin secretion in rats. Endocrinology 152(10):3628-3637

22. Riva M, Nitert MD, Voss U, Sathanoori R, Ling C, Wierup N (2011) Nesfatin-1 stimulates glucagon and insulin secretion and beta-cell NUCB2 is reduced in human type 2 diabetic subjects. Cell Tissue Res 346(3):393-405

23. Tarasov A, Dusonchet J, Ashcroft F (2004) Metabolic regulation of the pancreatic beta-cell ATP-sensitive $\mathrm{K}^{+}$channel: a pas de deux. Diabetes 53:S113-S122

24. Miyazaki J, Araki K, Yamato E, Ikegami H, Asano T, Shibasaki Y, Oka Y, Yamamura K (1990) Establishment of a pancreatic beta cell line that retains glucose-inducible insulin secretion: special reference to expression of glucose transporter isolation. Endocrinology 127:126-132

25. Minami K, Yano H, Miki T, Nagashima K, Wang CZ, Tanaka H, Miyazaki JI, Seino S (2000) Insulin secretion and differential gene expression in glucose-responsive and -unresponsive MIN6 sublines. Am J Physiol Endocrinol Metab 279:773-781

26. Yada T, Sakurada M, Ihida K, Nakata M, Murata F, Arimura A, Kikuchi M (1994) Pituitary adenylate cyclase activating polypeptide is an extraordinarily potent intra-pancreatic regulator of insulin secretion from islet beta-cells. J Biol Chem 269(2):1290-1293

27. Manaka K, Nakata M, Shimomura K, Rita RS, Maejima Y, Yoshida M, Dezaki K, Kakei M, Yada T (2014) Chronic exposure to valproic acid promotes insulin release, reduces $\mathrm{K}_{\mathrm{ATP}}$ channel current and does not affect $\mathrm{Ca}^{2+}$ signaling in mouse islets. $\mathrm{J}$ Physiol Sci 64(1):77-83

28. Li QC, Wang HY, Chen X, Guan HZ, Jiang ZY (2010) Fasting plasma levels of nesfatin- 1 in patients with type 1 and type 2 diabetes mellitus and the nutrient-related fluctuation of nesfatin-1 level in normal humans. Regul Pept 159(1-3):72-77

29. Guo Y, Liao Y, Fang G, Dong J, Li Z (2013) Increased nucleobindin-2 (NUCB2) transcriptional activity links the regulation of insulin sensitivity in Type 2 diabetes mellitus. J Endocrinol Invest 36(10):883-888

Publisher's Note Springer Nature remains neutral with regard to jurisdictional claims in published maps and institutional affiliations. 